\title{
Scale interactions in the tropical Atlantic variability simulated with a coupled GCM
}

\author{
William D. Cabos Narváez, Francisco J. Álvarez García and María J. Ortiz Beviá \\ Departamento de Física, Facultad de Ciencias, Universidad de Alcalá, Madrid, Spain
}

\begin{abstract}
Warm and cold events in the Gulf of Guinea are an important feature in the interannual variability of the tropical Atlantic Ocean, and partly a manifestation of the equatorial Atlantic system's intrinsic variability. Due to the relatively reduced zonal extension of this ocean, the latter variability is comparatively weak and thus strongly modified by other factors at play, either local or remote, like the seasonal cycle or ENSO. We present here an analysis of the tropical Atlantic variability in a 100-year-long chunk of the output of a coupled GCM. Through it, we obtain a better understanding of this variability and of its interactions with the seasonal cycle and with the ENSO signal. Following hints in the observations, we separate warm or cold events of the simulation in a few types, according to their similarities and differences. This classification is carried out as a spatio-temporal cluster analysis of the values, from nine months before up to the peak of the event, of the heat content anomalies. This is an optimal variable to monitor the generation of the events. One of the warm event classes can be explained by ENSO interactions. One of the cold event types can be explained by this influence as well, while the seasonal interactions might explain the characteristics of another of them.
\end{abstract}

Key words coupled model - Gulf of Guinea events - El Niño-Southern Oscillation - timescale interactions - clusters

\section{Introduction}

Recent years have seen a notorious increase in the interest of the scientific community in the interannual variability of the tropical Atlantic. Observational analyses (Stramma and England, 1999; Tourre et al., 1999), modelling of the observed variability (Carton et al., 1996), coupled models of the atmosphere and the ocean (simple (Xie, 1999), hybrid (Chang et al., 2001) or

Mailing address: Dr. William D. Cabos Narváez, Departamento de Física, Facultad de Ciencias, Universidad de Alcalá, Alcalá de Henares, Madrid 28871, Spain; e-mail: william.cabos@uah.es general circulation models (Dommenget and Latif, 2000)) and predictability studies (Penland and Matrosova, 1998), all of them have contributed to enhance our knowledge of the phenomena that take place in this ocean and are responsible for its variability at different time scales. Meridional displacements of the intertropical convergence zone constitute the main characteristic of the seasonal cycle of the tropical Atlantic. As for the interannual variability, its most outstanding feature are the warm and cold events in the Gulf of Guinea, that suggest an Atlantic counterpart for the Pacific ENSO (El Niño-Southern Oscillation). Additionally, there is an important decadal variability, associated with a 'dipole pattern', that explains roughly a $12 \%$ of the variability of the climatology-subtracted Sea Surface Temperature (hereinafter SST) field (Servain, 1991).

Several signs seem to indicate that scale interactions might be more relevant to the variability of the tropical Atlantic than to that of 


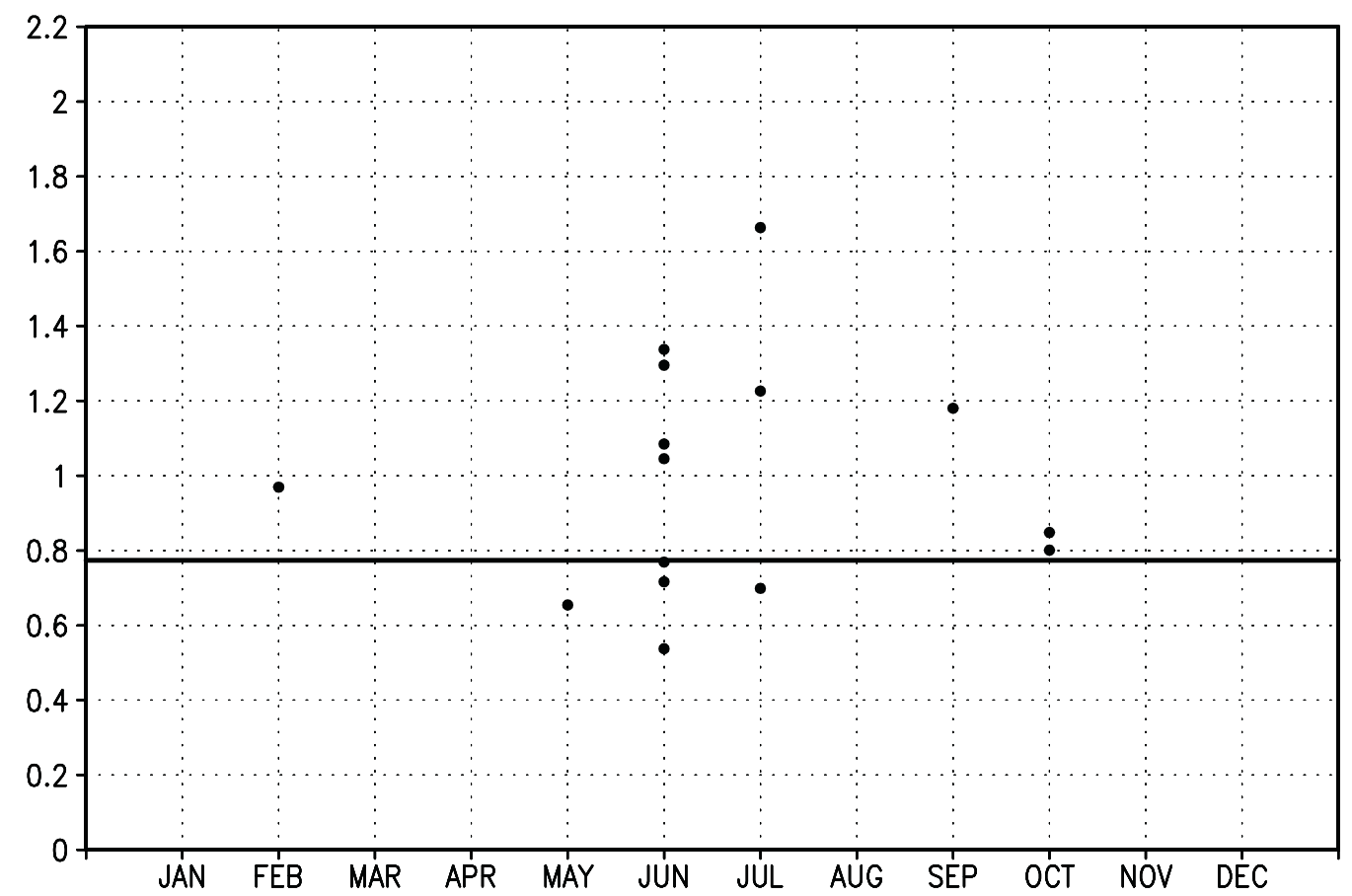

(a)

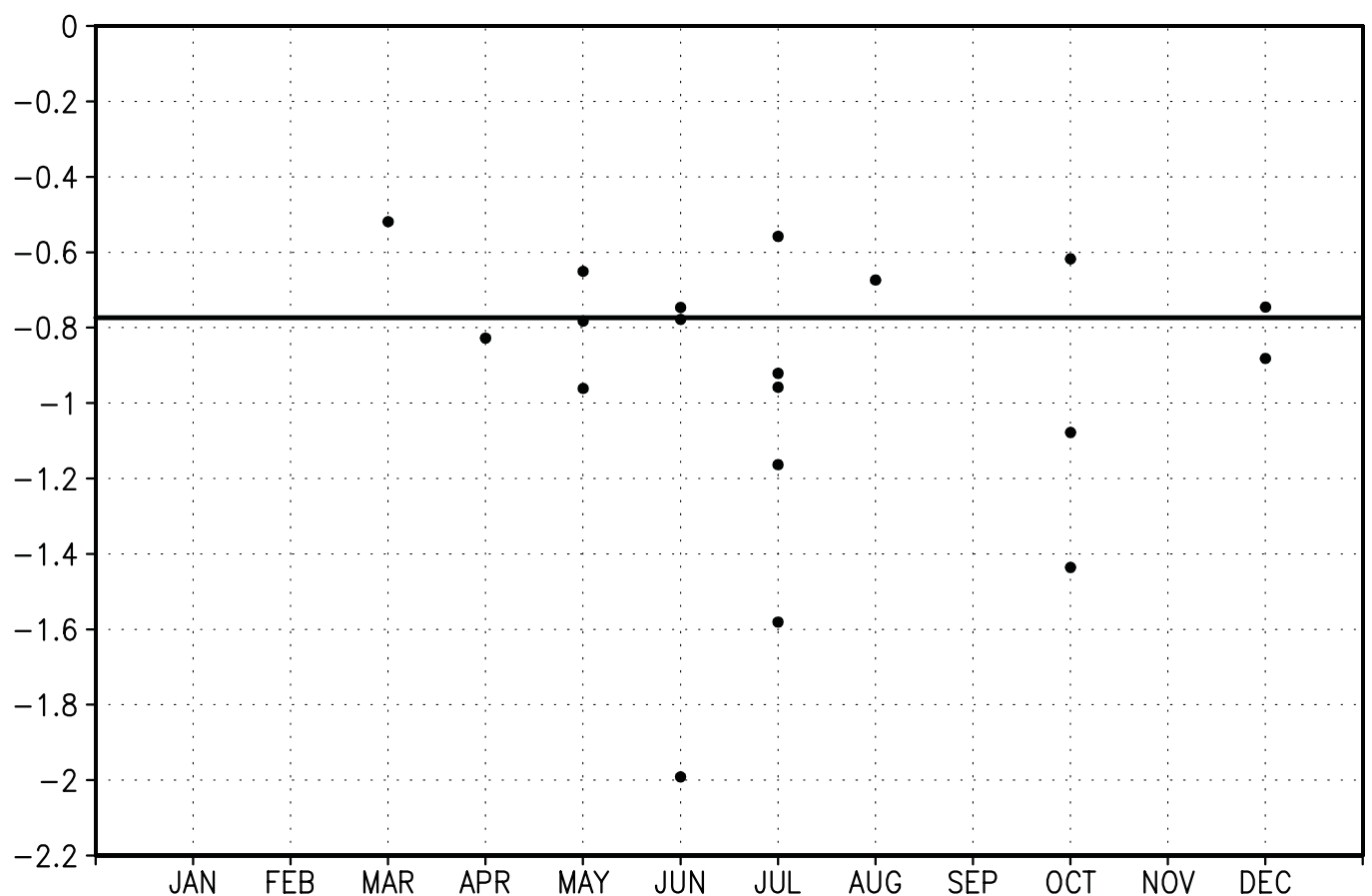

(b)

Fig. 1a,b. a) Seasonal distribution of warm SST anomaly peaks in the observed SST anomalies (COADS + IGOSS, 1950-1999). The horizontal line for the 1.5 standard deviation threshold is depicted in order to emphasize the stronger events; b) as in (a), but for the cold SST anomaly peaks. 
other oceans, particularly the Pacific: i) patterns of meridional gradient are linked to the first annual harmonic of the seasonal cycle and to the second Empirical Orthogonal Function of the seasonal anomalies, respectively. ii) The interannual warm and cold events are actually phaselocked to the seasonal cycle. The occurrence of these events is usually monitored by the Gulf of Guinea (hereinafter GG) Index, built as an average of the SST anomalies in the GG region $\left(20^{\circ} \mathrm{W}-10^{\circ} \mathrm{E}, 5^{\circ} \mathrm{S}-5^{\circ} \mathrm{N}\right)$. As shown in our fig. 1a,b, both warm and cold events peak during late spring-summer of the Northern Hemisphere (May-June-July) with few exceptions. iii) The correlation between the unfiltered GG Index and Niño3 Index is barely significant. This last Index, that characterizes the ENSO variability, is computed by averaging the anomalies of SST in the Niño3 region $\left(150^{\circ} \mathrm{W}-90^{\circ} \mathrm{W}, 5^{\circ} \mathrm{S}-5^{\circ} \mathrm{N}\right)$. If a low-pass filter is applied to these indices, removing variability with periods shorter than one year, the correlation between them notably rises. The GG Index typically lags, though not all Atlantic warmings are preceded by a corresponding ENSO episode.

In the present work, we try to understand how other scales, either temporal (the seasonal cycle) or spatio-temporal (ENSO variability), exert their influence, if effectively any, on the interannual variability of the tropical Atlantic: can they, in particular, affect the generation of the GG events? To answer this question, we will analyze the development of the latter in 100 years of a coupled GCM simulation. We are aware that such simulations still exhibit some unrealistic features, but on the other hand they offer the advantage of a far more satisfactory sampling than is available for observations as well as the certitude about the consistency of the generated data. The fundamental physical variable for our analysis is the thermal energy stored in the upper layers of the ocean or 'heat content', which previous studies (Chao and Philander, 1993; Latif and Graham, 1992) have shown to be the optimal parameter to trace the generation of the events.

The interannual variability of the equatorial Atlantic from 1980 through 1989 was simulated by Cabos Narváez et al. (1998), who found striking differences in the generation of the two warm events that took place in this decade.
While the 1984 event displayed the typical accumulation of warm off-equatorial $\mathrm{HC}$ anomalies in the west, in contrast to the cold ones in the GG, during its antecedent stage, the 1988 episode was characterized by the presence of positive HC anomalies in the GG already one year in advance of its peak. Simulations of the same period (Carton et al., 1996) with other ocean models confirm these differences are not an artifact of a particular ocean GCM or of the forcing used. Subsequently, Cabos Narváez et al. (2002) have investigated similarities and differences in the generation of the warm and cold events in a coupled GCM experiment with ECHAM4(T42)OPYC. The spatio-temporal analysis pursued there is applied in the present work to data produced by another coupled GCM, the ECHAM4(T30)-ORCA.

Details of the analyzed run will be given in Section 2. The classification technique we utilize is described in Section 3. The results for the warm events are specified in Section 4, while those for the cold events can be found in Section 5. In Section 6 we discuss how the different kinds of events are related to interactions with the seasonal cycle or with ENSO. We conclude with a summary and discussion.

\section{Data and method}

The data used for this study were basically those extracted from the output of the SINTEX experiment performed with the ECHAM4 atmospheric model (Roeckner et al., 1995) at T30 resolution coupled to the ORCA (global version of OPA8.1 (Madec et al., 1998)) oceanic model. Although differences between the observed and simulated mean state are still important in some regions (for instance the eastern equatorial Pacific), the simulated ENSO variability seems to be well represented (Gualdi et al., 2003). In the tropical Atlantic, the occurrence of the events is also quite realistic, though their magnitude is underestimated. The connection between the equatorial Pacific and Atlantic oceans appears to be correctly modelled, as shown by our fig. 2 , where we have represented the lagged correlation between the Niño3 and the GG Index in the observations and in the SINTEX run. We have 


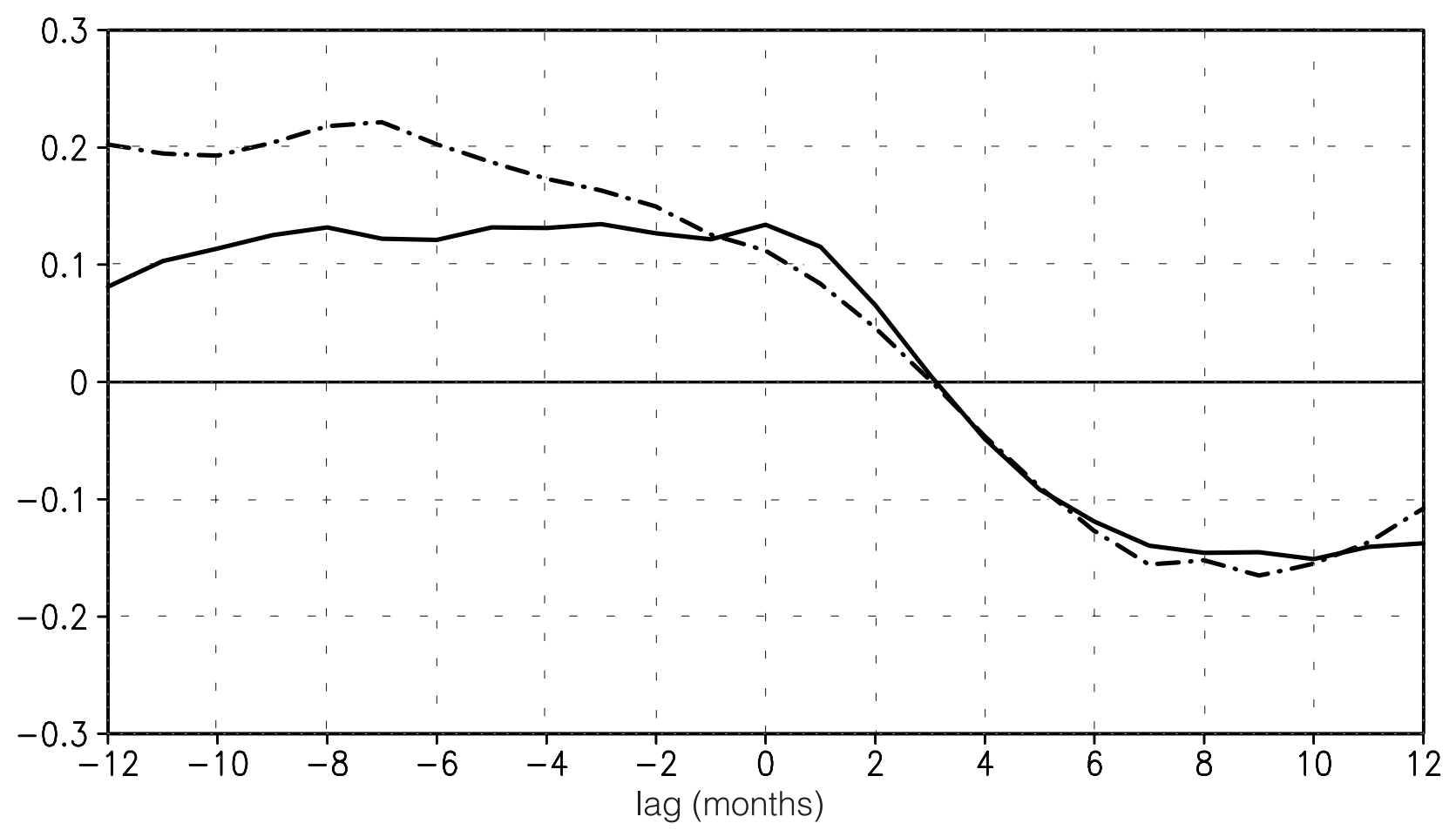

Fig. 2. Lagged correlation between the Niño3 and the GG Indices (Niño3 leading at negative lags), for both the SINTEX simulation (solid line) and the COADS + IGOSS observed SST anomalies (dot-dash line).

also examined the correlation maps (not shown) at one season lag between the Niño3 Index and the SST anomaly field in the tropical Atlantic, for both observed and simulated data. There is considerable agreement between these spatial patterns, confirming our belief that the impact of ENSO in the tropical Atlantic is adequately captured.

No trend in surface or subsurface variables was found in the 100 years chunk of simulated tropical Pacific variability selected for our study. This was also true for the surface variables of the tropical Atlantic, while a very slight trend was noticeable in the subsurface. This trend was removed for the purposes of the present analysis.

One of the basic variables for our analysis is the SST. The other, as stated above, is the thermal energy stored in the upper oceanic layers, defined by

$$
H C\left(t, \vec{r}_{H}\right)=\rho c_{p} \int_{h_{0}}^{0}\left(T\left(t, \vec{r}_{H}, \lambda\right)\right) d z
$$

the depth $h_{0}$ taking the value of $300 \mathrm{~m}$.
Results from Cabos Narváez et al., (2002), will be mentioned later in this paper. They applied the methodology used here to 200 years of data simulated with the ECHAM4-OPYC3 coupled model (Roeckner et al., 1995). Its atmospheric component has a T42 resolution, while the oceanic component has a comparable zonal resolution but a much coarser vertical discretization (only eleven layers). In a recent intercomparison study of 16 models (Achuta Rao et al., 2000), this CGCM simulation was rated among the best for its simulated seasonal cycle, the statistical characteristics of several climatic indices, the SOI-Niño3 teleconnections, the phase locking to the seasonal cycle, and the global atmospheric response to ENSO events. Some deficiencies of the model, common to most of them, are warmer than observed SST anomalies in the tropical Pacific off the South American coast, and the overestimation of the biannual component of ENSO (Bacher et al., 1998).

Observed SST from a global data set covering the period 1950-1999 will also be considered for 
the sake of comparison. The data set is described in Sanchez Gomez et al. (2001).

As for the ENSO case, events are identified from the GG index as those periods when anomalies exceed the threshold of one standard deviation of the time series for more than three months, with the condition that two events cannot occur within the same year (Trenberth, 1997). This criterion identifies correctly the accepted warm events for the equatorial Atlantic (Zebiak, 1993) from the observed GG index. In the 100 years chunk analyzed, 51 warm events and 46 cold events were identified. The highest peak in the GG SST anomaly during the period of occurrence of an event will be used as reference from now on, as detailed below.

Once the events have been identified, we proceed to their classification. We apply an agglomerative cluster analysis based on the minimization of the following distance between two events

$$
d_{p q}^{l}=+s_{p q}^{l}
$$

with

$$
s_{p q}^{l}=\frac{\sum_{j=1}^{N} y_{p j}(y) y_{q j} l}{\sqrt{\left(\sum_{j=1}^{N} y_{p j}^{2}(\gamma) /{ }_{j 1}^{N} y_{q j}^{2}(\phi)\right.}}
$$

where $y_{p}(l)$ and $y_{q}(l)$ stand for the spatial patterns of the $\mathrm{HC}$ anomalies in the Atlantic basin within $15^{\circ} \mathrm{S}$ and $15^{\circ} \mathrm{N}$ for events $p$ and $q$ respectively, $l$ months before their respective peaks in the SST anomaly GG index. Thus defined, the distance $d_{p q}^{l}$ will vary between 0 and 2 . The delay $l$ is computed with respect to the peak of each event. That is, in the following, month -1 , for instance, refers to the month previous to the peak, and month +1 to the one after.

The classification is carried out in two stages: at a first stabe, when clusters are still undefined, values of for every pair of events, with $l$ ranging between -9 and 0 months, are computed. An average (over $l$ ) of these distances is used to establish the initial groups, which are formed by a few events (typically 4 or 6 ) with minimum distance (under a threshold of 0.3) among them. Each group is then characterized by a composite at each lag $l$ and on the second stage the distance to these composites is computed for all the events that remain unclassified. Each one is aggregated to its nearest group, using as a criterion the distance averaged over the values of $l$ from -6 to 0 , chosen for the sake of a more distinct classification. The latter's robustness, however, has been examined, with positive results, by using other intervals within the $(-9,0)$ months range.

The number of events present in the sample analyzed gives barely two years as mean recurrence time between events, in good agreement with the observations. Also the time interval chosen for the cluster analysis points to a shortening of the generation period, in good accordance with the reduced dimensions of the Atlantic, as compared with the Pacific.

\section{The warm events generation}

The results of our classification of the warm events are summarized in table I. The 51 events are distributed among five groups, that are characterized by their HC composites at different lags. A greater diversity is found in this analysis for the Atlantic than in the one for the Pacific (see companion paper), which is also the case for the studies performed on the ECHAM4OPYC model, reported in Cabos Narváez et al. (2002) and Álvarez García et al. (2002). The statistical details of the clustering are satisfactory,

Table I. Warm events classification results. N1, D1, $\mathrm{S} 1$ : number of elements, average distance and standard deviation of the latter within a given group. N2, D2, S2: same as above for events outside a given group. $\mathrm{FV}$ : fractional contribution to the variance of the GG Index due to all warm events by those in a given group.

\begin{tabular}{cccccccc}
\hline \hline Group & N1 & D1 & S1 & N2 & D2 & S2 & FV \\
\hline I & 12 & 0.43 & 0.11 & 39 & 0.98 & 0.26 & $26 \%$ \\
II & 7 & 0.35 & 0.14 & 44 & 0.97 & 0.25 & $13 \%$ \\
III & 8 & 0.45 & 0.13 & 43 & 1.06 & 0.20 & $14 \%$ \\
IV & 5 & 0.37 & 0.13 & 46 & 1.08 & 0.24 & $11 \%$ \\
V & 7 & 0.39 & 0.12 & 44 & 0.93 & 0.27 & $12 \%$ \\
\hline
\end{tabular}


with values of the average distance within group plus its standard deviation always smaller than the average distance outside group minus its standard deviation.
In the Hoevmueller diagrams of fig. 3 we represent (top row) the evolution in time (measured with respect to the peak) of the $\mathrm{HC}$ composite at the equator for three out of the five
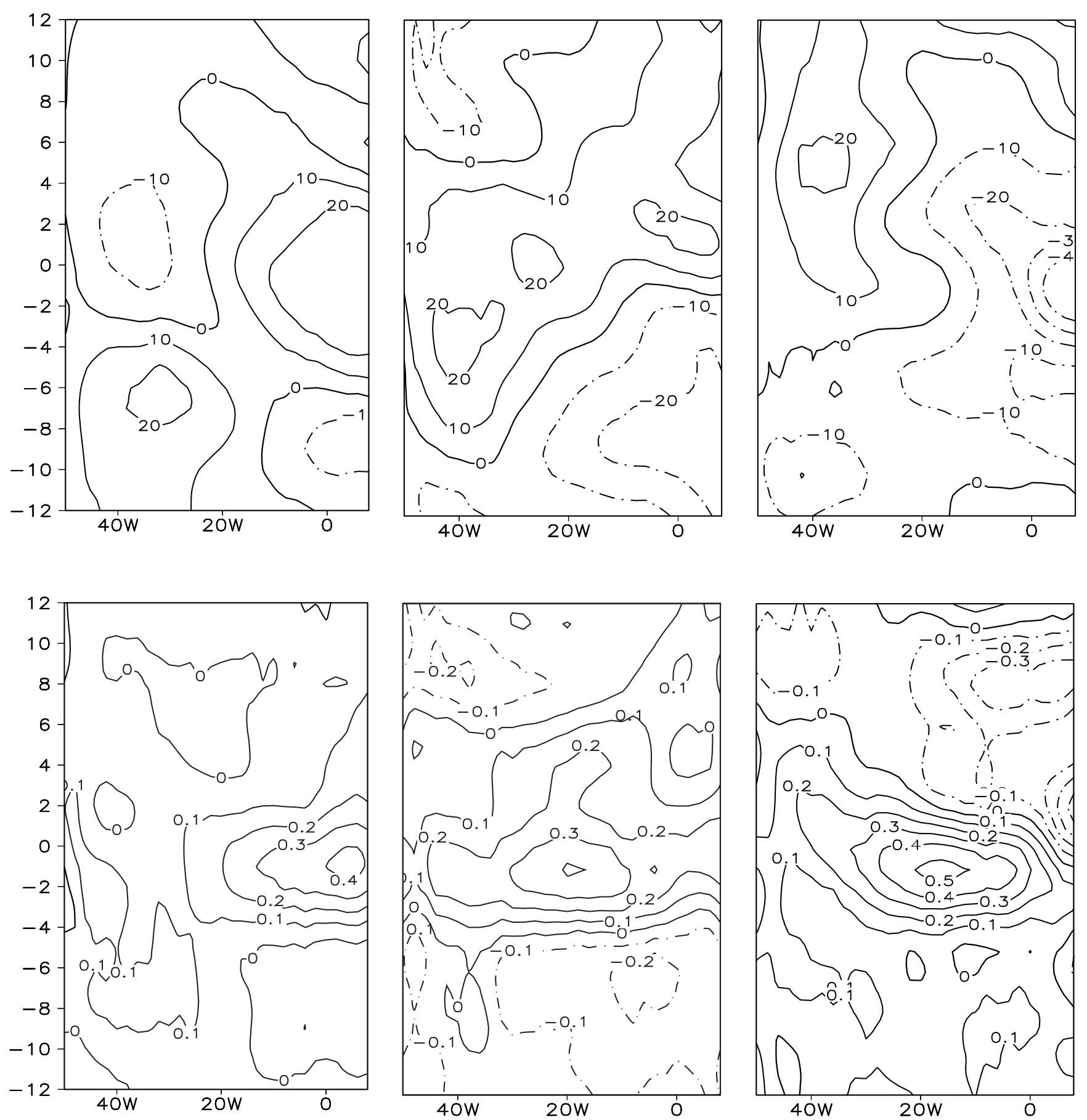

Fig. 3. Hoevmueller diagrams showing the evolution of (top) Heat Content $\left(10^{7} \mathrm{Jm}^{-2}\right)$ and (bottom) SST $\left({ }^{\circ} \mathrm{C}\right)$ anomalies in the equatorial Atlantic (averaged within the equatorial strip $5^{\circ} \mathrm{S}-5^{\circ} \mathrm{N}$ ) for warm events of type I (left), II (center) and IV (right). 
clusters identified. In the bottom row, the corresponding SST composites for each type are shown. In events of types I and II, there is an accumulation of anomalies of $\mathrm{HC}$ in the western part of the basin, nine months before the peak of the events. But while in events of type I HC anomalies have already propagated into the GG region by month -6 , in events of type II this propagation does not take place till month -3 . In events of type IV, $\mathrm{HC}$ anomalies are negative at the equator east of $20^{\circ} \mathrm{W}$ from month -9 up to the peak of the events, but positive SST anomalies are nevertheless produced in the GG. Such a situation is likely to correspond to a thin mixed layer lying above colder waters; atmospheric heat fluxes are distributed then over a smaller mass, yielding a stronger effect on the surface. This class of events has a counterpart among the cold ones (that is, characterized by cold SST along with positive anomalies of $\mathrm{HC}$ ), as will be shown. Events of type III (not shown) belong to a type that we will call 'static': warm HC anomalies can be found at the equator, east of $10^{\circ} \mathrm{W}$, already in month -9 , while SST anomalies are still cold in the region (but positive off the African coast south of $8^{\circ} \mathrm{S}$ ). They bear some likeness to cold events type III, whose behaviour is depicted in fig. 5 .

The evolution of $\mathrm{HC}$ anomalies in events of type $\mathrm{V}$ (not shown) is roughly similar to that of events type II, only the pattern of SST anomalies is considerably different now, strong positive SST anomalies being more confined to the eastern equator.

\section{The cold events generation}

Using the same criterion as above, 46 cold events are identified from the GG index of the 100 years of simulation analyzed. We apply to them a classification procedure identical to the one followed in the case of the warm events. Cold events appear to be generated according to four different ways. The statistical details of this classification are given in table II, where it can be appreciated how the distance between the centers of each cluster exceeds the value of the average distance within a group plus one standard deviation. Figure 4 shows the most characteristic
Table II. Cold events classification results. N1, D1, S1, N2, D2, S2, FV: same as in table I but for cold events.

\begin{tabular}{cccccccc}
\hline \hline Group & N1 & D1 & S1 & N2 & D2 & S2 & FV \\
\hline I & 9 & 0.33 & 0.13 & 37 & 1.06 & 0.26 & $25 \%$ \\
II & 6 & 0.26 & 0.10 & 40 & 0.98 & 0.28 & $18 \%$ \\
III & 12 & 0.40 & 0.10 & 34 & 1.08 & 0.30 & $27 \%$ \\
IV & 9 & 0.38 & 0.06 & 37 & 1.15 & 0.24 & $16 \%$ \\
\hline
\end{tabular}

features of the HC (top row) and SST anomalies (bottom row) for cold events type I, II and IV. The first two of them are similar in the same way warm events of type I and II are: there is an accumulation of negative $\mathrm{HC}$ anomalies in the west, north and south of the equator and there are positive $\mathrm{HC}$ anomalies in the GG region by month -9 . As shown in the corresponding Hoevmueller diagram of the fig. 4 , there is a gradient of $\mathrm{HC}$ anomalies along the equator, that is more pronounced in events of type I, likely as fallow-up of a previous warm event. This gradient is maintained up to month -6 in events type $\mathrm{I}$, but has already disappeared by that time in events of type II, all the equator being covered by negative HC anomalies. Events of type III are the negative counterpart to the warm events of type III, as mentioned above: there are negative $\mathrm{HC}$ anomalies in the GG region more than six months in advance of the peak; their in situ growth finally leads to the cold SST event, as shown in fig. 5. Events of type IV are characterized by the existence of positive $\mathrm{HC}$ anomalies in the GG during the cold SST episode, which supports the view that cold SST anomalies appear as a consequence of the subduction of warm surface waters.

\section{Seasonal and ENSO influence}

Figure 6a represents the seasonal distribution of the simulated warm events. We note in the first place their agreement with the seasonal distribution of the warm events in the observations (fig. 1a), only peaks tend to occur earlier in the model, in spring rather than in late spring. 

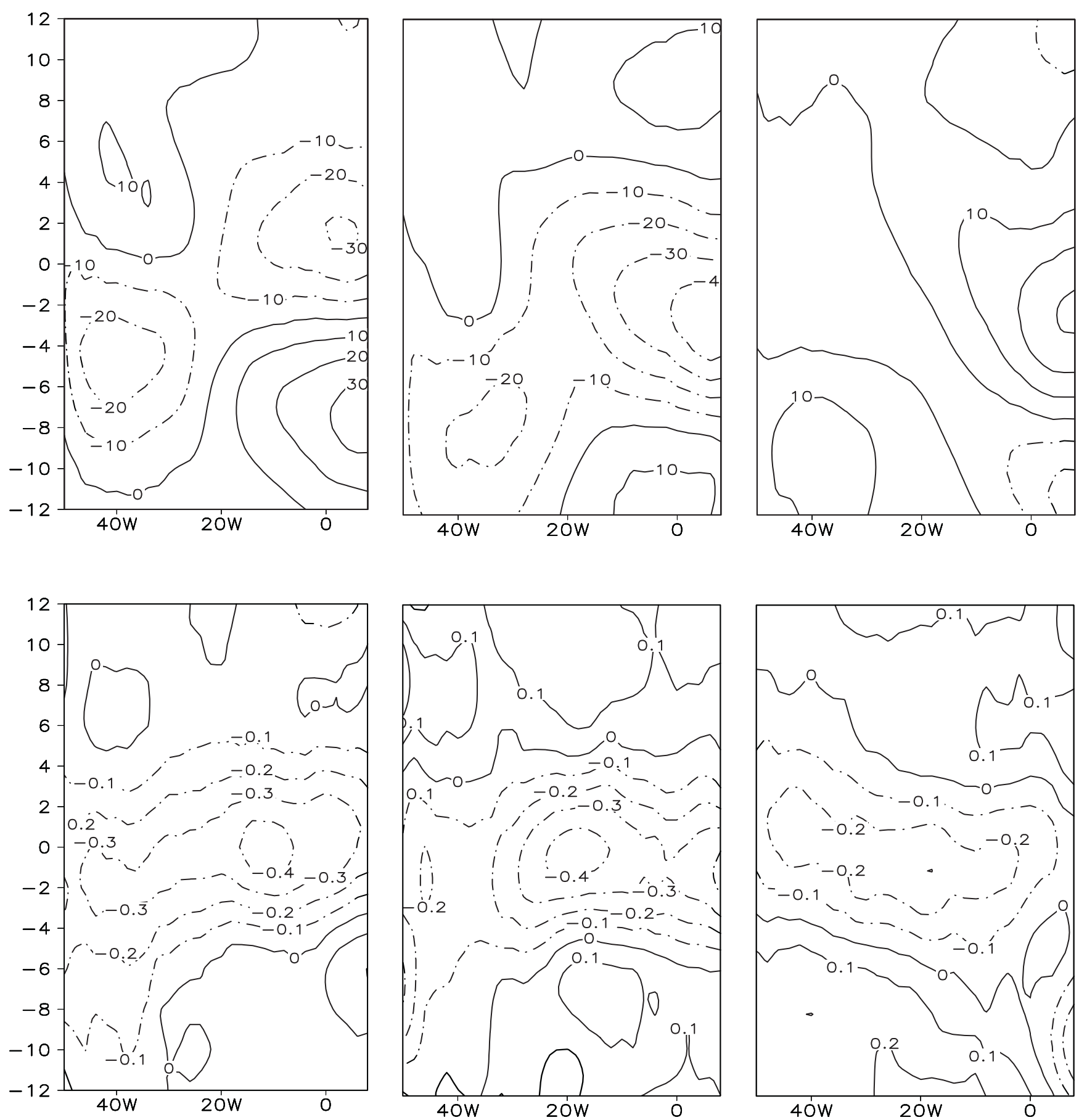

Fig. 4. Hoevmueller diagrams showing the evolution of (top) Heat Content $\left(10^{7} \mathrm{Jm}^{-2}\right)$ and $($ bottom $) \operatorname{SST}\left({ }^{\circ} \mathrm{C}\right)$ anomalies in the equatorial Atlantic (averaged within the equatorial strip $5^{\circ} \mathrm{S}-5^{\circ} \mathrm{N}$ ) for cold events of type I (left), II (center) and IV (right).

Warm events of a given type do not show any preferred seasonal signature. The corresponding seasonal distribution for the simulated cold events appear in fig. $6 \mathrm{~b}$. Notice how the events that take place in spring belong mostly to type IV, and how events of type III happening in the first half of the year are stronger than those in the second half. 

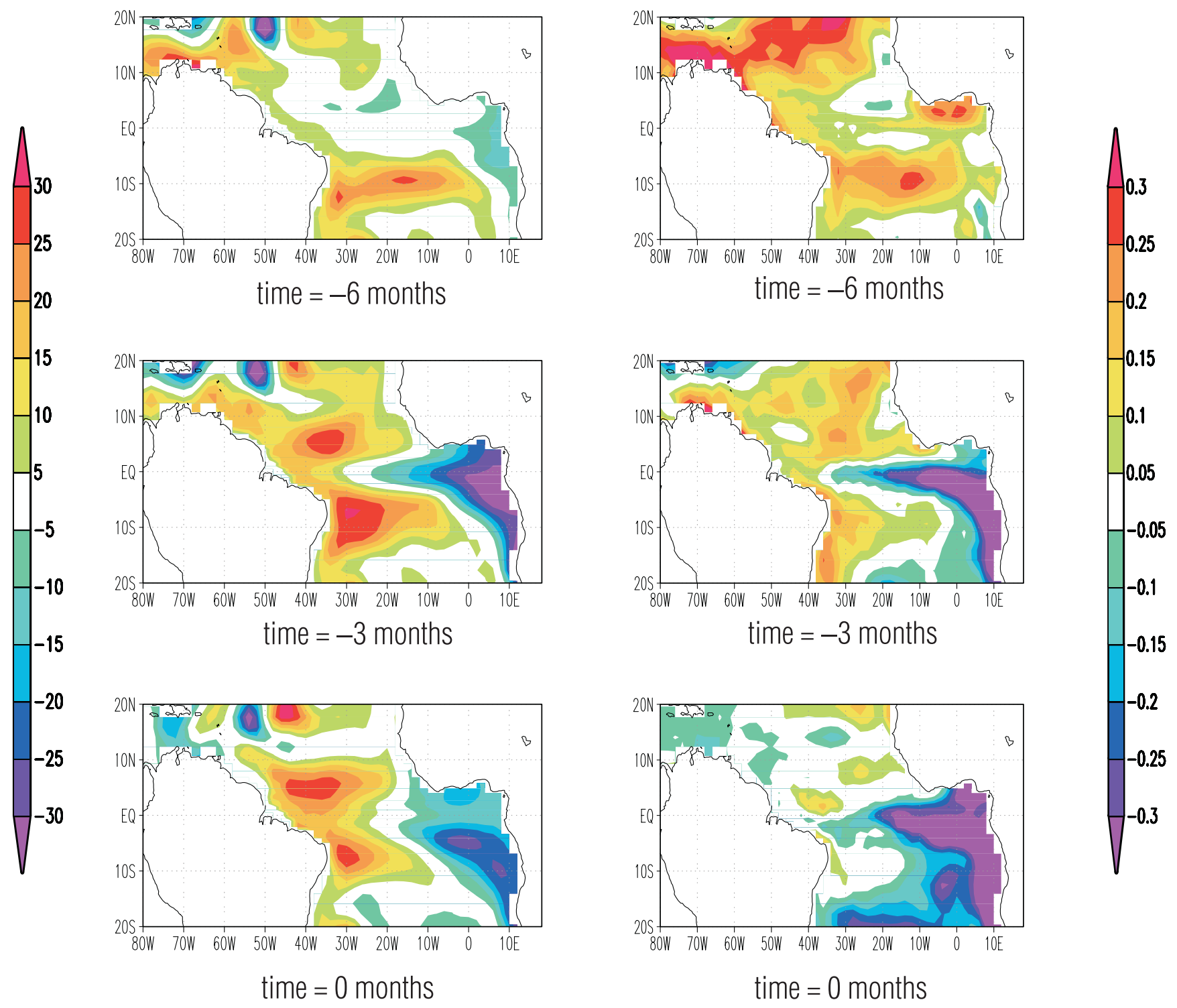

Fig. 5. Evolution of HC (left) and SST (right) anomalies for cold events of type III. Time is measured with respect to the peak in the SST (in month 0 ). Units are $10^{7} \mathrm{Jm}^{-2}$ and ${ }^{\circ} \mathrm{C}$, respectively.

To study the ENSO interaction, we computed the correlation at different lags between SST anomalies of the Niño3 Index and the GG Index isolating the periods of occurrence of events of distinct types (juxtaposing 19-month-long segments centered at the peak of the events). Figure 7a displays the correlations for the different types of warm events. For those of group IV, correlation with ENSO starts to be significant with the latter leading by 2 months, and peaks at zero months lead. Events of type I are also preceded by ENSO some 4 months in advance, but their correlation is weaker. Turning to fig. $7 b$, cold ENSO events seem to exert a stronger effect on the cold GG events rather than on the warm ones. Events of type I are apparently preceded by cold ENSO episodes almost one year in advance, while events of type IV begin to show significant correlations when ENSO is leading them by some 3 months. The maximum value of this correlation is attained at zero months lead. Events of type II follow warm ENSO events, while the events of type III (the 'static' ones) do not seem to be connected to ENSO in any way. 


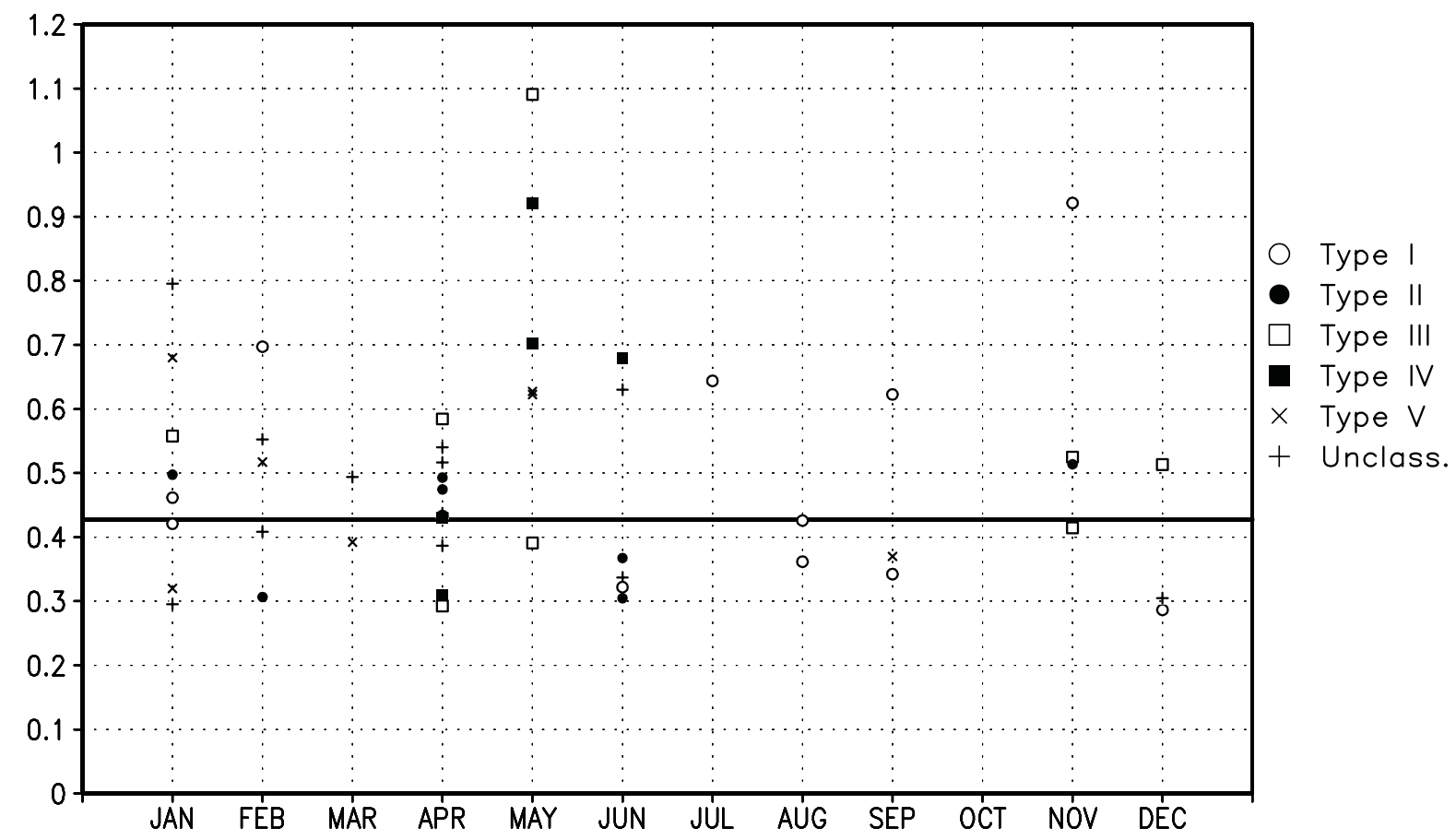

(a)

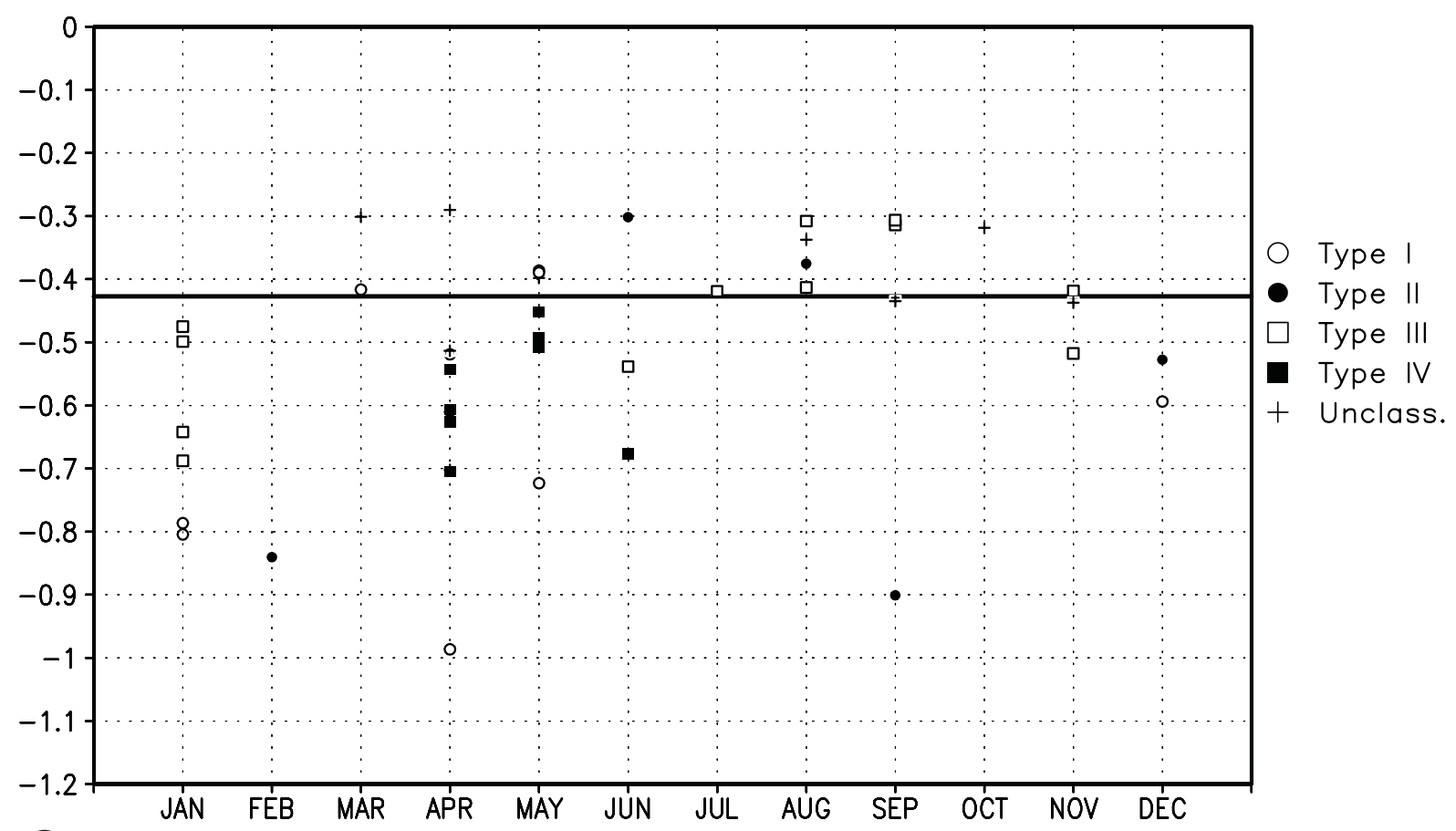

(b)

Fig. 6a,b. a) Seasonal distribution of warm SST anomaly peaks in the SINTEX simulation GG Index. The horizontal line for the 1.5 standard deviation threshold is depicted in order to emphasize the stronger events; $b$ ) as in (a), but for the cold SST anomaly peaks. 

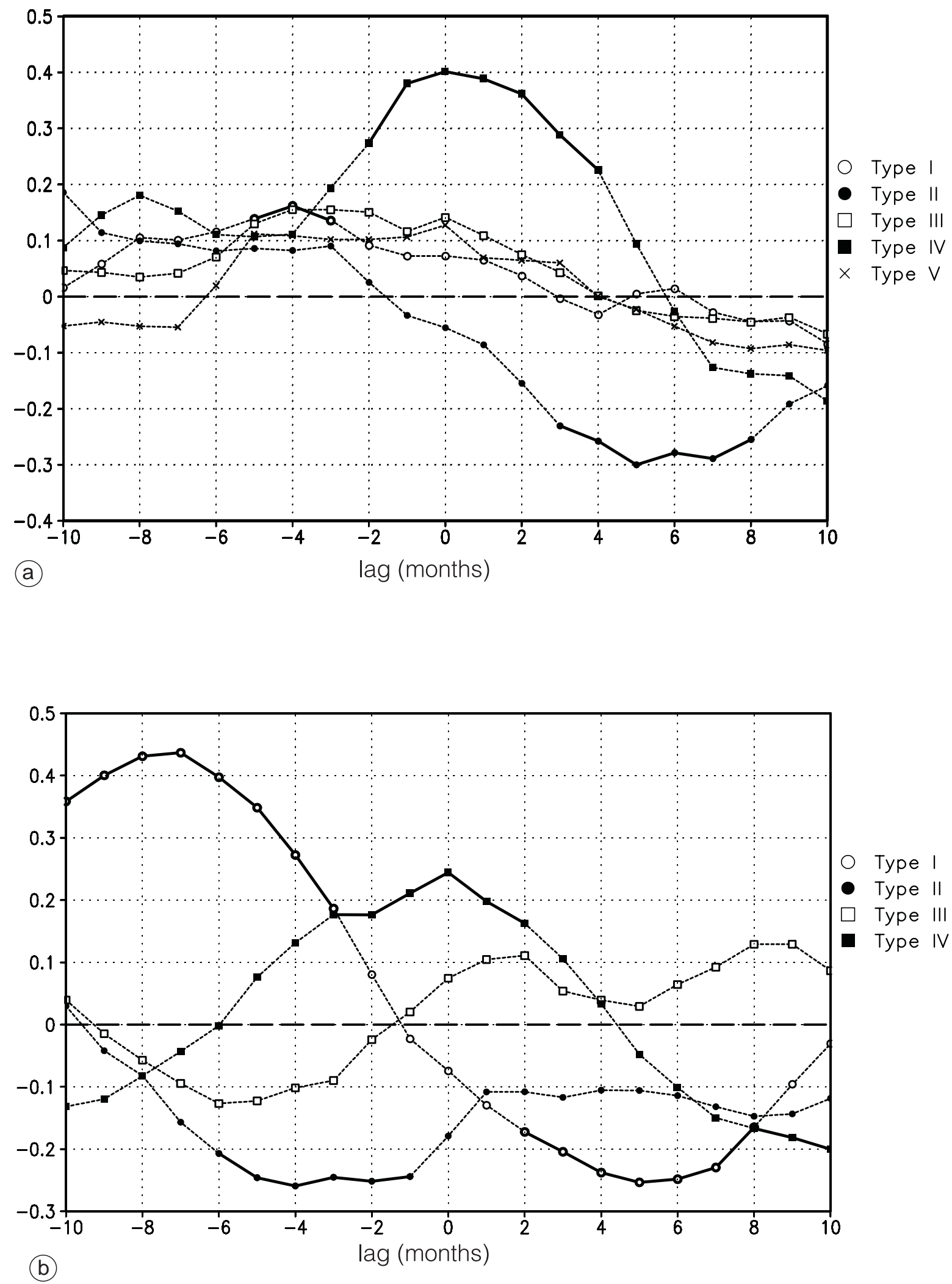

Fig. 7a,b. a) Lagged correlation between the SINTEX simulation GG and Niño3 Indices (Niño3 leading at negative lags). Different time series have been formed by isolating the periods of occurrence of the distinct types of warm GG events. Solid thick lines correspond to correlation values significantly greater than zero at the 5\% level; b) as in (a), now for cold GG events. 


\section{Summary and discussion}

Equatorial Atlantic warm (cold) events have been identified from the simulated GG Index. For each event, the $\mathrm{HC}$ patterns from 9 months before the peak of the event till the peak itself were separated. All of them were considered samples of the warm event generation, and subjected to a spatio-temporal statistical classification procedure. This analysis identifies five (four) types in the generation of warm (cold) events. When the same analysis was applied to the study of the ENSO variability in the SINTEX experiment (see companion paper), the number of types was smaller. This increase in the variety of types in the tropical Atlantic with respect to the Pacific also appears in the analysis, with the same technique, of another coupled simulation experiment (Cabos Narváez et al., 2002; Álvarez García et al., 2002). The statistical properties of the classification are satisfactory in all cases, regardless of how many classes are established.

All four cold event types seem to possess a counterpart among the five warm event classes. Warm events of types I and II are characterized by a gradient of $\mathrm{HC}$ anomalies along the equator, nine months before the peak of the events. Cold events of types I and II are, likewise, characterized by a gradient of $\mathrm{HC}$ anomalies along the equator of reverse sign. The difference between these two types of warm (cold) events lies in the pace at which the positive (negative) HC anomalies of the west propagate into the GG. In warm (cold) events of type III, warm (cold) HC anomalies can be found in the GG more than six months before the event peaks. As they grow in situ, those events are called here 'static'. Lastly, warm (cold) events of type IV are mainly distinguished by the feature that their $\mathrm{HC}$ and SST anomalies in the GG are of opposite signs. With a few exceptions, events in the observations are locked to the seasonal cycle, with a manifest preference to peak in late spring. This usually occurs earlier in the SINTEX run, in spring, an error which might stem from deficiencies in the simulation of the mean state, with modelled temperatures in the GG warmer than observed ones. The fact that this problem is also present in the other simulation analyzed supports this hypothesis.
Interaction with ENSO is important for events of type IV (warm or cold). The generation of warm events of type I is also, though more faintly, affected by it, at greater lead times. More generally, ENSO has a stronger effect on Atlantic cold events than on warm ones. The physical mechanism that exerts these influences is being examined.

\section{Acknowledgements}

This work was supported by contract ENV4CT98-0714 (SINTEX) from the European Union Environmental and Climate program.

\section{REFERENCES}

ACHUTA RAO, K., K.R. SPERBER, and the CMIP MODELLING Group (2000): The El Niño-Southern Oscillation in Coupled GCMs, PCMDI Report Series 61, pp. 46.

Álvarez García, F.J., W.D. Cabos NARvÁEZ and M.J. ORTIZ BEVIÁ (2002): Different kinds of ENSO generation in coupled GCM simulations, Climate Dyn. (in revision).

BACHER, A., J.M. OBERHUBER and E. ROECKNER (1998): ENSO dynamics and seasonal cycle in the tropical Pacific as simulated by the ECHAM4-OPYC3 coupled general circulation model, Climate Dyn., 14, 431-450.

Cabos Narváez, W.D., M.J. Ortiz Beviá and J.M. OBERHUBER (1998): The variability of the tropical Atlantic, J. Geophys. Res., 103, 7475-7489.

Cabos Narváez, W.D., F.J. Álvarez García and M.J. ORTIZ BEVIÁ (2002): Generation of equatorial Atlantic warm and cold events in a coupled GCM simulation, Tellus A, 54, 426-438.

Carton, J.A., X. CaO, B.S. Giese and A.M. De Silva (1996): Decadal and interannual SST variability in the tropical Atlantic Ocean, J. Phys. Oceanogr., 26, 1165-1175.

Chang, J.A., L. Ji and R. SARAVAnan (2001): A hybrid coupled model study of tropical Atlantic variability, $J$. Climate, 26, 361-1175.

CHAO, Y. and S.G.H. PHILANDER (1993): On the structure of the Southern Oscillation, J. Climate, 6, 450-469.

DOMMENGET, D. and M. LATIF (2000): Interannual to decadal variability in the tropical Atlantic, J. Climate, 13, 777-792.

Gualdi, S., A. NAVARRA, E. GuILYARDi and P. DeleCluse (2003): Assessment of the tropical Indo-Pacific climate in the SINTEX CGCM, Ann. Geophysics, 46 (1), 1-26 (this volume).

LATIF, M. and N.E. GRAHAM (1992): How mach predictive skill is contained in the thermal structure of an OGCM?, J. Phys. Oceanogr., 22, 951-962. 
MadeC, G., P. DeleCluse, M. Imbard and C. LeVy (1998): OPA Version 8.1 ocean general circulation model reference manual, Tech. Rep., LODYC/IPSL Note 1.1.

Penland, C. and L. Matrosova (1998): Prediction of tropical Atlantic Sea Surface Temperature using linear inverse modeling, J. Climate, 6, 1067-1076.

RoECKNER, E., J.M. OBERHUBER, A. BACHER, M. CRISTOPH and I. KIRCHNER (1995): ENSO variability and atmospheric response in a global coupled oceanatmosphere GCM, Max Planck Institut für Meteorologie, Report n. 170, Hamburg.

SANCHEZ GOMEZ, E., F.J. Álvarez GARCÍA and M.J. ORTIZ BEVIÁ (2001): Empirical seasonal forecasts of $850 \mathrm{hPa}$ air temperature anomalies, Quart. J. Meteorol. Soc., 127, 2761-2786.

SERVAIN, J. (1991): Simple climatic indices for the tropical
Atlantic Ocean and some applications, J. Geophys. Res., 96, 15,137-15,146.

STRAMMA, L. and M. ENGLAND (1999): On the water masses and mean circulation of the South Atlantic Ocean, $J$. Geophys. Res., 104, 20,863-20,883.

TOURRE, Y.M., B. RAJAGOLAPAN and Y. KushniR (1999): Dominant patterns of climate variability in the Atlantic Ocean during the last 136 years, J. Climate, 12, 22852299.

Trenberth, K.E. (1997): The definition of El Niño, Bull. Amer. Meteorol. Soc., 78, 2771-2777.

XIE, S.P. (1999): A dynamic ocean-atmosphere model of the tropical Atlantic decadal variability, J. Climate, 12, 64-70.

ZEBIAK, S.E. (1993): Air-sea interaction in the equatorial Atlantic region, J. Climate, 6, 1567-1586. 